\title{
ANAESTHETIC MANAGEMENT OF ADRENOCORTICAL TUMOR EXCISION IN A PATIENT OF CUSHING'S SYNDROME
}

\author{
Ravi R¹, Shilpashri A. M², Uma B. R ${ }^{3}$, Harsha B. M4
}

HOW TO CITE THIS ARTICLE:

Ravi R, Shilpashri A. M, Uma B. R, Harsha B. M. "Anaesthetic Management of Adrenocortical Tumor Excision in a Patient of Cushing's Syndrome”. Journal of Evolution of Medical and Dental Sciences 2015; Vol. 4, Issue 55, July 09; Page: 9681-9684, DOI: 10.14260/jemds/2015/1398

ABSTRACT: About 15\% of adrenocortical adenomas are functional leading to excess production of gluco-corticoids, sex hormones and mineralocorticoids. Exposure to excess of these hormones at an early age might lead to childhood hypertension and Cushing's syndrome. Airway management, electrolyte imbalance and cardiovascular complications need to be meticulously assessed and a proper plan is to be formulated for administering anaesthesia to these patients. Here we are reporting one such case of unilateral adrenocortical tumor excision in an 18 month old female child, presenting with Cushingoid features, childhood hypertension and difficult airway.

KEYWORDS: Adrenocortical tumor, Anaesthetic management, Cushing's syndrome.

INTRODUCTION: Cushing's syndrome is a clinical entity resulting from adrenocortical hyper function due to excessive exposure to glucocorticoids. Corticosteroid excess may be primary, secondary or iatrogenic. Primary is because of adrenal adenomas/ hyperplasia, Secondary due to ACTH secreting tumors. Iatrogenic cause being the commonest, due to exogenously administered corticosteroids. Most of the adenomas are incidentalomas (85\%), discovered on imaging performed for reasons unrelated to adrenal pathology. Only 15\% of these tumors might lead to symptoms of childhood hypertension and Cushing's syndrome, leading to significant morbidity and mortality if left untreated. The removal of adrenal gland or resection of the tumor is the options available for the treatment. Airway management, electrolyte imbalance and cardiovascular complications are the major challenges faced by an anesthetist during these surgeries.

CASE REPORT: An 18 month old female was referred with complaints of excessive weight gain, excess body hair growth, aggressive behaviour, irritability, deepening of voice and excessive feeding over the past four months. Patient had Cushingoid features and hirsutism along with hypertension. Endocrine pathology was suspected and thorough investigations were done. USG abdomen depicted large right suprarenal hypoechoic solid mass $7 \mathrm{~cm} \times 5 \mathrm{~cm}$. CT abdomen showed right adrenal mass of $6.7 \times 5.8 \mathrm{~cm}$ with no invasion, calcification and necrosis.

Over a period 2-3 weeks, antihypertensives were given and hypertension was reduced after which BP levels fell within $9^{\text {th }}$ percentile for the age and length to the present value of 104/68. Patient was planned for right adrenocortical tumor excision with replacement therapy of glucocorticoids.

On the day of surgery, 22G cannula was placed in the upper limb and patient was put on maintenance drip of isolyte $\mathrm{P}$ in the ward. Morning dose of antihypertensives were given. Inj. Hydrocortisone $25 \mathrm{mg}$ IV was given before shifting to the operation theatre. Monitors were attached for continuous monitoring of $\mathrm{NIBP}, \mathrm{SPO}_{2}, \mathrm{ECG} \mathrm{EtCO} 2$ and $\mathrm{HR}$. Weight of the patient was $12 \mathrm{~kg}$, height was $77 \mathrm{~cm}$ (2 SD). Pre-operative heart rate was 111 beats/min, BP 120/76mm of Hg, $\mathrm{SPO}_{2}-94 \%$. 
Patient was premedicated with Inj. Glycopyrrolate $0.1 \mathrm{mg}+\mathrm{Inj}$. Pentazocine 5mg IV Inj. Ondansetron $1 \mathrm{mg}$ IV+Inj. Ranitidine $12.5 \mathrm{mg}+\mathrm{Inj}$. Midazolam $0.5 \mathrm{mg}$. After proper preoxygenation patient was induced with propofol $1 \% 30 \mathrm{mg}$ and relaxed with Inj. Succinylcholine $25 \mathrm{mg}$ IV. Trachea was intubated with $5 \mathrm{~mm}$ uncuffed portex endotracheal tube. Inspite of cushingoid features and short neck intubation was easy. After confirming bilateral entry, the endotracheal tube was fixed. Arterial line was placed in left radial artery for continuous monitoring of BP. Internal jugular venous cannulation could not be done because of short neck and indistinct land marks. One more peripheral line was secured in the lower limb.

A 19G epidural catheter was inserted in L3-4 space with $3 \mathrm{~cm}$ of catheter in epidural space and $5 \mathrm{ml}$ of $0.25 \%$ of Inj. Bupivacaine was given after the test dose. Maintenance of anaesthesia was done by positive pressure ventilation with $\mathrm{O}_{2}$ and $\mathrm{N}_{2} \mathrm{O}$ as 50\%: $50 \%$ along with supplemental doses of Vecuronium+Isoflurane.

Intraoperatively, due to meticulous surgical dissection and adequate depth of anaesthesia, there was no major blood pressure fluctuation during tumor manipulation.

There was no major blood loss and no blood transfusion was required. Arterial blood gas analysis and blood sugar levels were normal. Urine output was also maintained throughout the procedure.

At the conclusion of the surgery, patient was reversed with Inj. Neostigmine $0.5 \mathrm{mg}$ and Inj. Glycopyrrolate $0.1 \mathrm{mg}$ IV. Patient was fully awake, maintaining her vitals. Post-operative analgesia was continued through epidural catheter. Patient was shifted to PICU for continuous monitoring. Postoperative steroid cover was continued on subsequent postoperative days. Patients BP and blood glucose levels gradually came to near normal levels. Patient was discharged on $16^{\text {th }}$ postoperative day.

DISCUSSION: Adrenocortical tumors might present with Cushing's syndrome and childhood hypertension. Cushing's syndrome patients present with increased body weight, truncal obesity with buffalo hump, easy bruisability, cutaneous striae, oedema, hypokalemia, glucose intolerance. All these presentations make these patients a challenge to anaesthetics. ${ }^{1}$

Approximately $40 \%$ of endogenous causes of Cushing's syndrome are ACTH producing pituitary tumors and ACTH producing non-pituitary tumors such as tumors of the lung, prostate, testis, parotid or pancreas. Nearly $25 \%$ of cases are due to adrenal hyperplasia, without ACTH secreting tumors. $20 \%$ of patients with endogenous Cushing's have adrenocortical tumors, about half of which are benign adenomas. ${ }^{2}$

Our patient presented with Cushingoid features and was diagnosed to have functional adrenocortical tumor.

Preoperatively hypertension in the patient was managed with salt restricted diet and by putting her on drugs like Methyldopa, Amlodipine, Enalapril and with oral Labetalol. Hyperglycaemia is also an important consideration in these patients due to high cortisol levels and needs to be controlled preoperatively 3 but our patient had normal blood sugar level preoperatively, thus no active intervention was required for it.

Goals of anaesthetic management in these surgeries should be aimed to provide optimal surgical condition and to suppress the responses to endotracheal intubation, surgical stimulation, tumor handling and devascularisation.,2 So, we preferred general anaesthesia combined with epidural anaesthesia. 
Steroid cover was mandatory in the perioperative period. The adrenocorticotrophic hormone (ACTH) secretion by the pituitary is suppressed. The inability of the suppressed hypothalamic pituitary-adrenal (HPA) axis to respond to perioperative stress can lead to acute adrenal insufficiency and cardiovascular collapse. So glucocorticoid replacement therapy should be initiated at the start of surgery at a dose equal to full replacement of adrenal output that is the period of extreme stress. ${ }^{5}$ Therefore steroid therapy was instituted by giving Inj. Hydrocortisone $2 \mathrm{mg} / \mathrm{kg}$ given immediately before surgery and followed by $3-5 \mathrm{mg} / \mathrm{hr}$ infusion perioperatively and continued postoperatively.

Pre-medication should be adequate and drug causing histamine release should be avoided. Thiopentol sodium, propofol or inhalational agents such as sevoflurane should be preferred. Succinylcholine was used for intubation, as we expected difficult intubation. Muscle relaxation was continued with Inj. Vecuronium because of its hemodynamic stability and non-release of histamine. Perioperative hemodynamic variation was controlled by combing regional anesthesia with general anaesthesia using isoflurane and narcotics. ${ }^{6}$ we used epidural anesthesia with general anesthesia to provide preemptive and post-operative analgesia. Blood pressure and heart rate surges during tumor handling need potent vasodilators, for which sodium nitroprusside and nitroglycerine were kept ready.

Postoperative monitoring of blood sugar, Serum electrolyte is very important. Immunity of the patients is very poor and they are very prone for sepsis and DIC. ${ }^{7}$ so intraoperatively and postoperatively asepsis was maintained. Serial monitoring of blood sugar, electrolytes and CBC were done. There was no problem in our patient except blood glucose levels, which gradually normalized subsequently in postoperative days. Patient was discharged on the $16^{\text {th }}$ postoperative day.

Diagnosis and management of adrenocortical tumor is a real challenge. Early involvement of anesthesiologist is very important. The fine skills of a surgeon, combined with good pre-operative optimization and post-operative care by a pediatrician and anesthesiologist can help in successful management of these kinds of cases.

\section{REFERENCES:}

1. Kurt D. Newman. Todd Pousky. Diagnosis and management of endocrine tumors causing hypertension in children. Annals of New York Academy of Sciences 2000; 970: 155 -158.

2. P. V. Waghalkar, KA Raman, KV Singh, N Rajpal, S Pandya, MB Garasia, L V Dewoolkar Anaesthetic management of bilateral adrenal hyperplasia in a pediatric patient. The Internet Journal of Anesthesiology 2007; 13 (2): DOI: 10. 5580/2045.

3. Robert K. Stoelting, Stephen F. Dierdorf. Anaesthesia and co -existing disease, $4^{\text {th }}$ edn. p. 425 426.

4. Mina Basu, Sampa Datta Gupta, Soma Mukhopadhyay, Subrata Saha. Anaesthetic management of bilateral phaeochromocytoma in a young female patient. Indian Journal of Anaesthesia 2007; 51 (3): 237 -239.

5. A. Kulkarni, G. Rastogi, A. Bhargava. Anaesthetic management of resection of a cortisol secreting tumor. Cushing's syndrome, perioperative steroid replacement. The Internet Journal of Anesthesiology 2007; 14 (1): DOI: 10.5580/2643.

6. Poonam Gupta, AR Gogia, R. Wasson. Anaesthetic management of bilateral phaeochromocytoma in a child-a case report. Indian Journal of Anaesthesia 2005; 49 (1): 54 -55. 


\section{CASE REPORT}

7. Usha Badole, Ketaki Patwardhan, Surabhi Maheshwari, Rupali Bhalerao. Anaesthetic management of laparoscopic adrenaloectomy for adrenocortical tumor in a paediatric patient A case report. The Indian Anaesthetists Forum July 2010: (1); 1 -7. Online ISSN 0973 -0311 http: //www. theiaforum. org.

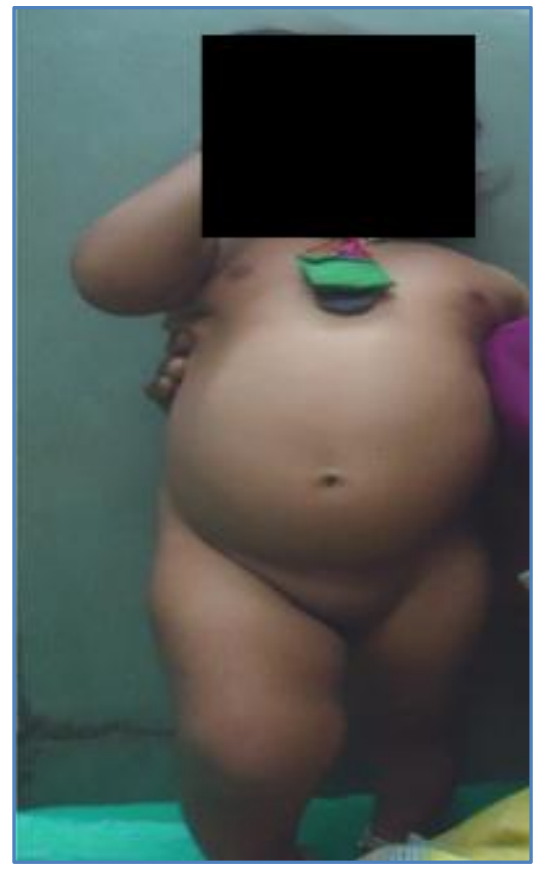

Fig. 1: 18 Months old child with Cushing's syndrome

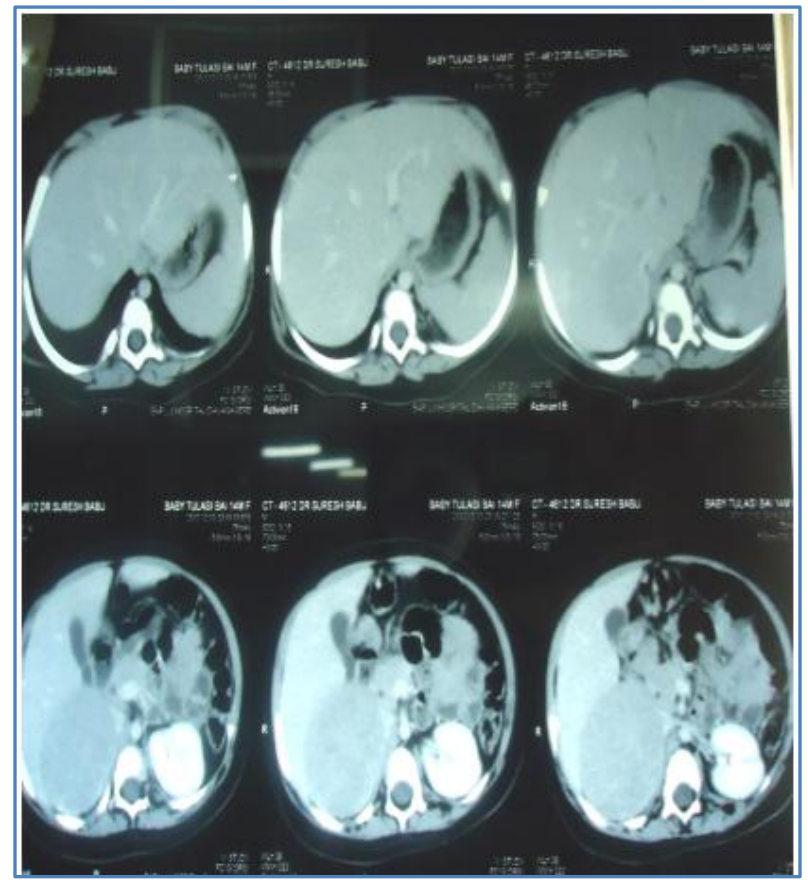

Fig. 2: CT abdomen

\section{AUTHORS:}

1. Ravi R,

2. Shilpashri A. M.

3. Uma B. R.

4. Harsha B. M.

\section{PARTICULARS OF CONTRIBUTORS:}

1. Professor \& HOD, Department of Anaesthesiology, J. J. M. Medical College, Davangere.

2. Associate Professor, Department of Anaesthesiology, J. J. M. Medical College, Davangere.

3. Associate Professor, Department of Anaesthesiology, J. J. M. Medical College, Davangere.

FINANCIAL OR OTHER COMPETING INTERESTS: None
4. Professor, Department of Paediatric Surgery, J. J. M. Medical College, Davangere.

\section{NAME ADDRESS EMAIL ID OF THE CORRESPONDING AUTHOR:}

Dr. Shilpashri A. M, \#1906, $2^{\text {nd }}$ Cross, S. S. Layout, 'A' Block, Davangere-577004.

E-mail: shilpashri.am@gmail.com

Date of Submission: 09/06/2015.

Date of Peer Review: 10/06/2015.

Date of Acceptance: 01/07/2015.

Date of Publishing: 09/07/2015. 